\title{
Time to recovery from Eclampsia and its determinants in east Gojjam zone hospitals, Amhara, Ethiopia, 2017/18
}

Bekalu Kassie $^{1 *}$, Yibelu Bazezew ${ }^{1}$, Yewbmirt Sharew ${ }^{1}$, Leltework Yismaw ${ }^{2}$, Melaku Desta ${ }^{1}$ and Muluneh Alene ${ }^{2}$

\begin{abstract}
Background: Eclampsia is a tonic clonic type of seizure among pre-eclamptic mothers. Time to recovery from eclampsia is to mean that the time when the mother recovered from severity features of pre-eclampsia. As far as the mother is not free from severity features, she is in a potential to end-up with repeated seizure (eclampsia). Therefore, combating eclampsia through controlling severity features is crucial to enhance maternal health quality, reduce maternal morbidity and mortality, and improve prenatal outcomes. There was no literature that describes the recovery time of eclampsia and its determinants in Ethiopia. Therefore, this study aimed to assess the recovery time from eclampsia and its determinants in East Gojjam zone hospitals.

Methods: An institutional based retrospective follow up study was conducted between January 2014 and December 2017 among 608 eclamptic mothers in East Gojjam zone Hospitals. Simple random sampling technique was used. Data were coded and entered to Epidata version 3.1 and was exported to SPSS version 20 and then to Stata 14. We used the adjusted hazard ratio (AHR) with 95\% confidence interval at $p$-value less than 0.05 to measure strength of association.
\end{abstract}

Result: The median recovery time of eclampsia was $12 \mathrm{~h}$ with inter-quartile range of ( $1-48 \mathrm{~h}$ ). The rate of recovery from eclampsia among mothers aged more than 20 years was reduced by half (AHR $0.50(0.28,0.89))$ than the teenagers. The rate of recovery from eclampsia among mothers who had prolonged labor was 1.3 times (AHR 1.26 $(1.01,1.57))$ than those whose labor was less than $12 \mathrm{~h}$. About $32 \%$ of mothers with multiple convulsions recoverd later than (AHR $0.68(0.52,0.87))$ those who had single convulsion. As compared to antepartum convulsion, the rate of recovery from postpartum eclampsia was 1.8 times faster (AHR 1.81(1.17, 2.81)).

Conclusion: The median recovery time from severity features among eclamptic mothers in East Gojjam zone hospitals was half a day. It is affected by age, duration of labor, number of convulsions and time of occurrence of the event. Special attention for elders, prevent recurrent convulsion and faster termination for the antepartum eclamptic mothers are recommended from this follow-up study.

Keywords: Eclampsia, Pregnancy induced hypertension, Time to recovery, East Gojjam, Ethiopia

\footnotetext{
* Correspondence: bekalukassiedmu@gmail.com

'Department of Midwifery, College of Health Sciences, Debre Markos University, Debre Markos, Ethiopia

Full list of author information is available at the end of the article
}

(C) The Author(s). 2021 Open Access This article is licensed under a Creative Commons Attribution 4.0 International License, which permits use, sharing, adaptation, distribution and reproduction in any medium or format, as long as you give appropriate credit to the original author(s) and the source, provide a link to the Creative Commons licence, and indicate if changes were made. The images or other third party material in this article are included in the article's Creative Commons licence, unless indicated otherwise in a credit line to the material. If material is not included in the article's Creative Commons licence and your intended use is not permitted by statutory regulation or exceeds the permitted use, you will need to obtain permission directly from the copyright holder. To view a copy of this licence, visit http://creativecommons.org/licenses/by/4.0/ The Creative Commons Public Domain Dedication waiver (http://creativecommons.org/publicdomain/zero/1.0/) applies to the data made available in this article, unless otherwise stated in a credit line to the data. 


\section{Introduction}

Improving maternal and child health is a global priority [1] .The problem of maternal health during pregnancy is one with many special features as maternity is not a disease. Pregnancy and childbirth are privileged functions of women, essential for the survival of our species which is not being compared with other burdens of disease [2]. Maternal mortality is a key indicator of international development, and its reduction has long been a challenge in low-income countries, despite the existence of effective interventions [3].

Pregnancy and childbirth related complications are common problems that cause many women to die and suffer life-threatening difficulties that disable them [4-6]. Even if most of maternal deaths are preventable, maternal mortality rate is still high and it is the major public health problem in the world, especially in developing countries [7-9]. Globaly in the past two and a half decades, there was a significant progress in the declining maternal mortality $[4,5,7]$. In spite of this improvement, more than 289,000 women still die each year as a result of pregnancy and childbirth through pregnancy to the first 42 days of the postpartum period globally [4, 5, 7, 9]. Nearly all of these women live in poor nations where $99 \%$ of the global maternal death has been occurring in developing countries, mainly in the two developing regions, sub-Saharan Africa and southern Asia [5, 7]. Eclampsia is the development of generalized grandmal tonic clonic convulsions in a pregnant or puerperal woman, usually between 20 weeks' of gestation and the first $48 \mathrm{~h}$ of postpartum period, mostly in a woman with gestational hypertension or preeclampsia in the absence of other neurologic conditions [10, 11]. It is the most devastating type of Hypertension Disorders of pregnancy (HDP) [10].

Hypertensive disorders during pregnancy remains a significant public health problem throughout the world, and eclampsia is one of the most life-threatening complications of these disorders. HDP accounts for nearly $18 \%$ of all maternal deaths worldwide, with an estimated $62,000-77,000$ deaths per year (18). Eclampsia is a major health problem in developing countries and every year, eclampsia is associated with an estimated 50,000 maternal deaths Worldwide [12].

Around $70 \%$ of mothers with eclamsia develop life threatening complications which include abruption placentae, disseminated intravascular coagulopathy, acute renal failure, hepatocellular injury, liver rupture, intracerebral hemorrhage, transient blindness, cardio respiratory arrest, aspiration pneumonitis, acute pulmonary edema, postpartum hemorrhage and HELLP syndrome (Hemolysis, Elevated Liver enzymes, Low Platelet counts).
Ethiopia, is one of the six countries which has highest Maternal Mortality Ratios (MMR) in the world and currently, the Ethiopian MMR is 420/100,000 live births [13]. Most causes of these deaths are preventable including eclampsia. In Ethiopia, there is an overall increasing trend of maternal death due to hypertensive disorder of pregnancy [14-17].

Maternal Mortality Ratios (MMR) in Amhara Region are calculated at 266 deaths per 100,000 live births. Of the total maternal deaths recorded in the region, $8.1 \%$ is as the result of hypertensive disorder of pregnancy, which is the third common cause of maternal mortality following hemorrhage and anemia of pregnancy [17].

Delay in health care-seeking, distance to facility, delay in initiation of treatment, severity of complications, absence of antenatal care attendance and quality of care contributes to the majority of HDP related maternal deaths [18].

Reduction of maternal mortality is a priority program in the international arena and ending preventable maternal mortality is the main concern agenda of the sustainable developmental goals. Sustainable Developmental Goal (SDG), Goal 3, target 3.1 declared that MMR would be reduced to less than 70/100,000 live births by 2030, with no single country having an MMR greater than $140[9,19]$.

One of the activities is prevention, early detection and treatment of pregnancy related complications (9). To reduce maternal mortality rates, the government of Ethiopia is working by assigning trained health professional to all districts, giving training and refreshment course, allocating ambulance service to all districts and developing well organized referral linkage in all regions. Despite all these efforts, MMR is one of the highest in the world and Eclampsia still remains one of the leading causes of direct maternal mortality, even if it is preventable. So doing a research in this area is invaluable to provide evidence based practice to enhance maternal health, reduce maternal morbidity and mortality, and improve prenatal outcomes and also to improve the care in health care tier system because the outcome of Eclampsia is time dependent.

As of the authors' effort, there is no literature that describes the recovery time of eclampsia and its determinants in Ethiopia but also in the Africa. Therefore, this study was aimed to assess the average recovery time of eclampsia and its determinants in East Gojjam zone hospitals of Amhara region among women admitted with a diagnosis of eclampsia. Furthermore, the findings of this study will be helpful for health providers, police makers and other stakeholders and will be very helpful to be used as a baseline for further researches and also for educational purposes. 


\section{Methods}

All methods were carried out in accordance with relevant guidelines and regulations from study design to the analysis.

\section{Study design and setting area}

We conducted an institutional based retrospective follow up study to determine time to recovery of eclampsia and its determinants between January 2014 to December 2017 in East Gojjam zone hospitals. This zone is bordered on the south by the Oromia Region, on the west by Weast Gojjam, on the north of south Gondar, and on the east by South Wollo and the bend of the Abay River defines the zone's northern, eastern and southern boundaries. Its highest point is mount Choke. Based on the 2007 census conducted by the central statistical agency of Ethiopia, this zone has a total population of 2, 153,937 . In the administrative zone there are around 111 health institutions of which 8 are primary and 1 is referral hospitals. This study was conducted infour hospitals by taking mothers with eclampsia from 3 primary hospitals (Shegaw Motta Hospital, Bichena primary Hospital and Lumame primary hospital) and Debre Markos referal hospital.

In hospitals where we conducted this study, similar standard of treatment of eclamptic mother was there. All eclamptic women managed with antihypertensive and anticonvulsant medications besides the general and emergency managements. The commonly used anticonvulsant was magnesium sulphate while the antihypertensive was hydralazine. The target of management for these women is controlling severity features and keep vital organs well functioning.

Study population: All pregnant and postpartum mothers who were admitted to hospitals of the East Gojjam zone with the diagnosis of eclampsia within the last five years.

\section{Eligibility criteria}

Inclusion Criteria: mothers admitted to selected hospitals with a diagnosis of eclampsia during the study period were included.

\section{Sample size determination}

The sample size was determined by using sample size determination formula for time to event data based on the Cox's proportional hazards model sample size calculation with the assumptions of the null hypothesis ${ }_{\mathrm{Ho}_{\mathrm{o}}}$ : $\mathrm{b}=0$ and Alternative hypothesis $\left(\mathrm{H}_{\mathrm{a}}\right): \mathrm{b} \neq 0$.

$$
n=\frac{\left(Z_{\alpha / 2}+Z_{\beta}\right)^{2}}{b^{2} p_{1} p_{2} d}
$$

$\mathrm{n}=$ the required sample size; $Z_{\alpha / 2}=$ critical value of the standard and normal distributed variable at $5 \%$ significance level; $Z_{\beta}=$ critical value of standard normal distributed variable at $20 \%$ of $\beta ; \beta=$ the probability of type two error, $\mathrm{b}=\log$ (hazard ratio), $p_{1}=$ the proportion of the number of patients in the first category, $p_{2}=$ the proportion of number of patients in the second category and $d$ represents the proportion of the event. In this case the proportion of recovered patients from eclampsia, $d=97.1 \%$, which has been taken from a previous study [18].

The sample size was calculated by using the above formula considers six key factors based on a study conducted in Hawassa [18] and finally the maximum sample size is taken which is 552 and by adding $10 \%$ for those incomplete patient charts the final sample size become 608 .

\section{Sampling procedure and technique}

To select the required sample size, simple random sampling technique used. Data collectors select all eclamptic cases from a list of the patients' registration books between January 2014 to December 2017. Then samples allocated proportionally to each selected hospital. From all admitted eclamptic mothers in the selected hospitals (Debre Markos comprehensive specialized referral hospital, lumame primary hospital, Bichena primary hospital and Shegaw Mota General hospital) six hundred eight samples were selected proportionally.

\section{Operational definition}

Recovery: mothers diagnosed with eclampsia and has no cerebral symptoms AND creatinine level less than $1.1 \mathrm{mg} / \mathrm{dl}$ AND blood pressure less than 150/100 $\mathrm{mmHg}$, AND Aspartet aminotransferase and alanine aminotransferase enzymes level not more than two fold of normal range. AND is to indicate if the mother has either of the features the conclusion should be not recovered.

Time to recovery (survival time/ time-to-event): is the time from diagnosis of eclampsia to recovery.

Starting time: Time of diagnosis.

End time: Time of discharge of the patient/last recored on the patient chart/.

Censored: Lost to follow up and referred cases.

\section{Data collection tools and procedures}

Data were collected from the patient's chart by preparing a checklist which contains five major groups of variables: Maternal socio-demographic characteristics, laboratory results, management approaches, clinical symptoms/signs, and maternal and fetal outcomes until discharge. Eight midwives collected the data; two for each hospital after 2-days training given. 


\section{Data quality control}

To assure the data quality, data collection instruments designed with high emphasis. Regular meetings held between data collectors, supervisor and the principal investigator to discuss and solve problematic issues. We reviewed and checked the data for completeness before data entry.

\section{Data processing and analysis}

The collected data were coded and entered to Epidata version 3.1 and was exported to SPSS version 20 and then to STATA 14 for data clearance, transformation (recoding variables) and analysis purpose. In this study, the outcome/variable of interest was time until the mother recovered from severty features of preeclampsia. Hence, survival analysis was used to estimate survivor and/or hazard functions from survival data, to compare survivor and/or hazard functions and to assess the relationship between the explanatory variables to survival time. We used Kaplan-Meier to estimate the distribution of recovery time and to observe the experience of recovery time among each group for categorical covariates. Log-rank test was used for comparing the survival (recovery) experience between two or more groups. To identify determinant factors for recovery time, semi-parametric (Cox proportional hazard) and parametric methods used. Factors significantly associated with the outcome variable in single covariate analysis at $p$-value less than 0.2 were included in the multiple covariate analysis and statistically significant associations were measured by the Adjusted hazard ratio (AHR) with 95\% confidence interval at $p$-value less than 0.05 .

\section{Result}

In this retrospective follow-up study, about charts of 586 mothers admitted in 4 selected hospitals with the diagnosis of eclampsia between January 2014 to December 2017 were involved with a response rate of $96.4 \%$. Twenty-two of the reviewed charts were with incomplete information and considered as non-response rate. The median age of the study participants was 27 years and about $32 \%$ of them were in the age group of 25-29 years. More than $58 \%$ of them were rural residents. Among all eclamptic mothers who visited selected hospitals in East Gojjam zone, $47.8 \%$ were primiparous. Around $37 \%$ of participants faced eclampsia at a gestational age of 33 weeks or earlier. Of the total participants, $6.8 \%$ gave birth to twins while the rest were singletons (Table 1).

\section{Clinical management approaches}

All eclamptic mothers are managed based on the national guidline which includes mainly three components. First component is the general management which includes emergency mamnagement, progress assessment, and documentation. From the progress assessment, neurological evaluation score at admission by Glasgow Coma Scale (GCS) was the one. The minimum score of GSC was 2 with $0.5 \%$ and the maximum was 15 with mean score of 13.03 .

For controlling convulsion all mothers given anticonvulsant medications. About $94.4 \%$ of eclampsic mothers managed with magnesium sulphate while the rest took diazepam as anticonvulsant medication. For controlling hypertension, $80.50 \%$ of women given anti hypertensive while the $19.5 \%$ didn't take any antihypertensive medication. Of those who took antihypertensive, majority (68, $4 \%)$ were given hydralyzin followed by methyledopa (65.2\%) and nefidipine (12.3\%). From the total 586 eclamptic mothers, $25.8 \%$ gave birth by cesarean section for the indications of uncontrolled eclampsia (40.4\%), failed inductionnon (29.1\%), non-reassuring fetal heart rate $(25.5 \%)$, fetomarernal disproportion $(6.6 \%)$ and antepartum hemorrhage (3.97\%).

The definitive management of eclampsia was termination of pregnmancy. For termination cesarean section is not the only option rather induction of labor is also considerd as one mechanism of termination. All the decisions for termination options are based on the indications and pre-requesites. Majority $(55.63 \%)$ of women undergone with cesarean section took general anesthesia. From the total eclamptic mothers $79.4 \%$ had live births while the rest $20.6 \%$ lost their fetuses. Not only losing their fetuses but also they lost their lives (3.9\%).

In reduction of maternal mortality magnesium sulphate is better than diazepam. Of the total 553 mother who took magnesium sulphate only 20 (3.6\%) died while from 38 participants who took diazepam $15.79 \%(n=6)$ died.

Age category, gestational age, duration of labor, number of convulsions and convulsion to administration of anticonvulsant were significantly different in survival time at $5 \%$ level of significance.

Median recovery time of mothers from eclampsia varied among various categories of variables. For instance, in age, it varies from an hour to 1 day (Table 2). The survival curve tends to decrease rapidly within half a day indicating that most mothers have recovered from the problem within $12 \mathrm{~h}$ and slower over time (Fig. 1). Relatively it is in line with a study in Finland [20].

In the multivariable analysis, age of participants, duration of labor, number of convulsions and time of occurrence of convulsion found to be significantly associated with the time of recovery from eclampsia. The hazard of recovering late from eclampsia was about $50 \%$ among those aged from 20 to 24 years as compared to teenagers. Similarly, mothers aged from 25 to 29 years were 
Table 1 Socio-demographic and reproductive factors description among eclamptic mothers in East Gojjam zone hospitals

\begin{tabular}{|c|c|c|c|}
\hline Variables & Categories & Frequency & Percent \\
\hline \multirow[t]{6}{*}{ Age in years } & $16-19$ & 21 & 3.6 \\
\hline & $20-24$ & 151 & 25.8 \\
\hline & $25-29$ & 191 & 32.6 \\
\hline & $30-34$ & 107 & 18.3 \\
\hline & $35-39$ & 90 & 15.4 \\
\hline & $>=40$ & 26 & 4.4 \\
\hline \multirow[t]{2}{*}{ Residence } & Urban & 244 & 41.6 \\
\hline & Rural & 342 & 58.4 \\
\hline \multirow[t]{4}{*}{ Parity } & Nulliparous & 12 & 2.1 \\
\hline & Primiparous & 280 & 47.8 \\
\hline & Multiparous & 218 & 37.2 \\
\hline & Grand multiparous & 76 & 13.0 \\
\hline \multirow[t]{3}{*}{ Gestational age } & $<=33$ wks & 215 & 36.7 \\
\hline & 34-36 weeks & 140 & 23.9 \\
\hline & $>=37$ weeks & 231 & 39.4 \\
\hline \multirow[t]{2}{*}{ Type of pregnancy } & Singleton & 546 & 93.2 \\
\hline & Twin & 40 & 6.83 \\
\hline \multirow[t]{2}{*}{ ANC follow-up } & Yes & 525 & 89.6 \\
\hline & No & 61 & 10.4 \\
\hline \multirow[t]{2}{*}{ Mode of delivery } & SVD & 377 & 64.3 \\
\hline & Assisted delivery & 209 & 35.7 \\
\hline \multirow[t]{2}{*}{ Place of delivery } & Home & 30 & 5.12 \\
\hline & Institution & 556 & 94.9 \\
\hline \multirow[t]{2}{*}{ Duration of labor (464) } & $<=12 \mathrm{~h}$ & 310 & 66.8 \\
\hline & $>12 \mathrm{~h}$ & 154 & 33.2 \\
\hline \multirow[t]{2}{*}{ Initiation of labor } & Induced & 288 & 50.0 \\
\hline & Spontaneous & 288 & 50.0 \\
\hline \multirow[t]{2}{*}{ Number of convulsions } & Single & 443 & 75.6 \\
\hline & Multiple & 143 & 24.4 \\
\hline \multirow[t]{2}{*}{ Convulsion to administration of anticonvulsant } & Less than an hour & 428 & 73.0 \\
\hline & More than an hour & 158 & 27.0 \\
\hline
\end{tabular}

0.48 times to recover slowly from eclampsia as compared to those aged from 16 to 19 .

Mothers who were in labor for more than $12 \mathrm{~h}$ were 1.26 times more likely to recover faster from eclampsia than those who were in labor for less than $12 \mathrm{~h}$. Number of convulsion was the one factor that can increase the hazard of delaying the recovery from eclampsia. Mothers with multiple convulsion were 0.68 times more likely to recover too late from this problem.

The rate of recovery from eclampsia among mothers aged more than 20 years was reduced by half AHR 0.50 $(0.28,0.89)$ than the teenagers at any time in the follow up period. Those mothers who had prolonged labor was 1.3 times AHR $1.26(1.01,1.57)$ higher than those whose labor was less than $12 \mathrm{~h}$ to recover from the disease. The rate of recovery from Eclampsia among mothers with multiple convulsions were 32\% AHR 0.68 (0.52, 0.87) reduced than those who had single convulsion (Fig. 2). The rate of recovery of mothers from eclampsia among those who developed the disease at the postpartum period was 1.8 times AHR 1.81(1.17, 2.81) higher than the antepartum eclampsia (Table 3 ).

\section{Discussion}

The overall median recovery time from eclampsia (first documentation of the diagnosis to recovery from severity features) in this study was half a day. The rate of recovery from eclampsia among mothers aged more than 20 
Table 2 Comparison of survival time by using log rank test among eclamptic mothers in East Gojjam zone hospitals, 2018

\begin{tabular}{|c|c|c|c|c|c|}
\hline \multirow[t]{2}{*}{ Variables } & \multirow[t]{2}{*}{ Categories } & \multirow[t]{2}{*}{ Frequency } & \multirow{2}{*}{$\begin{array}{l}\text { Median recovery } \\
\text { time from eclampsia (hours) }\end{array}$} & \multicolumn{2}{|c|}{ Log rank test } \\
\hline & & & & $\mathrm{X} 2$ & $P$-value \\
\hline \multirow[t]{6}{*}{ Age in years } & $16-19$ & $21(3.6)$ & 1 & 12.05 & 0.03 \\
\hline & $20-24$ & $151(25.8)$ & 14 & & \\
\hline & $25-29$ & $191(32.6)$ & 24 & & \\
\hline & $30-34$ & $107(18.3)$ & 4 & & \\
\hline & $35-39$ & $90(15.4)$ & 4 & & \\
\hline & $>=40$ & $26(4.4)$ & 8 & & \\
\hline \multirow[t]{2}{*}{ Residence } & Urban & $244(41.6)$ & 8 & 0.77 & 0.38 \\
\hline & Rural & $342(58.4)$ & 12 & & \\
\hline \multirow[t]{4}{*}{ Parity } & Nulliparous & $12(2.1)$ & 24 & 0.96 & 0.81 \\
\hline & Primiparous & $280(47.8)$ & 14 & & \\
\hline & Multiparous & $218(37.2)$ & 8 & & \\
\hline & Grand multiparous & $76(13.0)$ & 4 & & \\
\hline \multirow[t]{3}{*}{ Gestational age } & $<=33$ weeks & $215(36.7)$ & 24 & 6.98 & 0.03 \\
\hline & 34-36 weeks & $140(23.9)$ & 4 & & \\
\hline & $>=37$ weeks & $231(39.4)$ & 6 & & \\
\hline \multirow[t]{2}{*}{ Type of pregnancy } & Singleton & $546(93.2)$ & 12 & 0.39 & 0.53 \\
\hline & Twin & $40(6.83)$ & 4 & & \\
\hline \multirow[t]{2}{*}{ ANC follow-up } & Yes & $525(89.6)$ & 7 & 0.69 & 0.40 \\
\hline & No & $61(10.4)$ & 24 & & \\
\hline \multirow[t]{3}{*}{ Mode of delivery } & SVD & $377(64.3)$ & 20 & 0.83 & 0.66 \\
\hline & $\mathrm{C} / \mathrm{S}$ & $148(25.3)$ & 4 & & \\
\hline & Assisted & $61(10.4)$ & 24 & & \\
\hline \multirow[t]{2}{*}{ Place of delivery } & Home & $30(5.12)$ & 3 & 0.01 & 0.93 \\
\hline & Institution & $556(94.9)$ & 12 & & \\
\hline \multirow[t]{2}{*}{ Duration of labor (464) } & $<=12 \mathrm{~h}$ & $310(66.8)$ & 24 & 7.45 & 0.01 \\
\hline & $>12 \mathrm{~h}$ & $154(33.2)$ & 3 & & \\
\hline \multirow[t]{2}{*}{ Initiation of labor } & Induced & $288(50.0)$ & 14 & 1.45 & 0.23 \\
\hline & Spontaneous & $288(50.0)$ & 8 & & \\
\hline \multirow[t]{2}{*}{ Number of convulsions } & Single & $443(75.6)$ & 4 & 13.79 & 0.001 \\
\hline & Multiple & $143(24.4)$ & 24 & & \\
\hline \multirow[t]{2}{*}{ Convulsion to administration of anticonvulsant } & Less than an hour & $428(73.0)$ & 6 & 4.01 & 0.045 \\
\hline & More than an hour & $158(27.0)$ & 24 & & \\
\hline
\end{tabular}

years was reduced by half as compared to teenagers at any time in the follow up period. This might be because the younger the age, the more organs to cope the disease. Meaning, organs of these young people have good capacity to cope the disorder than elders because survival of a patient depends on the damage level of vital organs.

Mothers who were in labor for more than $12 \mathrm{~h}$ were 1.26 times more likely to recover faster from eclampsia than those who were in labor for less than $12 \mathrm{~h}$. In other words, mothers in labor for more than $12 \mathrm{~h}$ were $26 \%$ more to recover from eclampsia than those who stayed for less than $12 \mathrm{~h}$ in labor.

Number of convulsion was one of the factors that can increase the hazard of delaying the recovery from eclampsia. Mothers with multiple convulsion were 0.68 times more to recover from this problem, which means $32 \%$ of mothers with multiple convulsions recovered later than mothers with singleconvulsion (Fig. 2). This might be because of the reason that the higher the number convulsions, the higher risk of vital organ damage which easily imply low rate of recovery. 


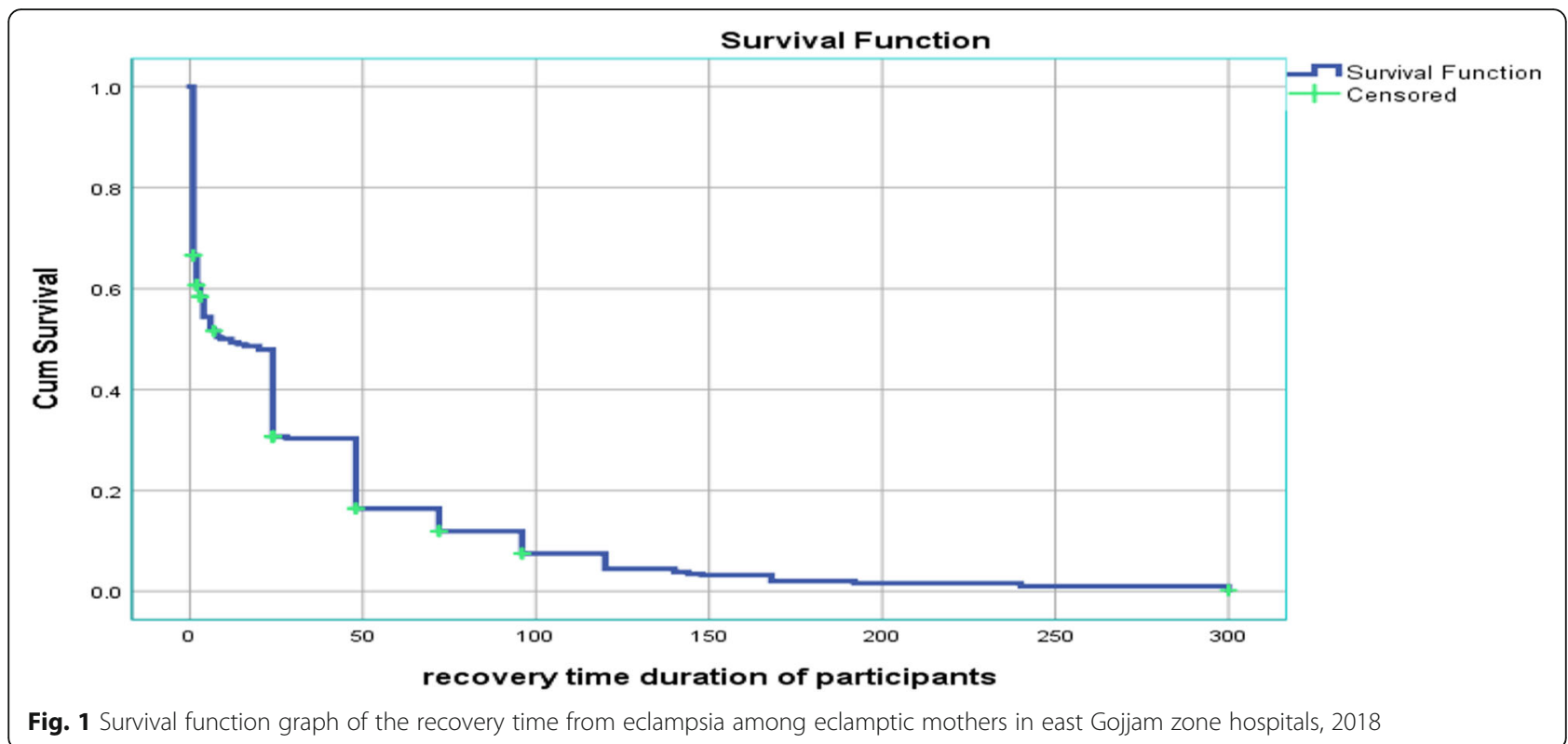

Those mothers who had prolonged labor was 1.3 times higher than those whose labor was less than $12 \mathrm{~h}$ to recover from the disease. This might be because women whose convulsion controlled are expected to give birth vaginaly by induction that takes more time to deliver while noncontrolled ones are expected to give birth through cesarean section. So if not controlled there will be delayed recovery.

The rate of recovery of mothers who developed eclampsia during the postpartum period was 1.8 times higher than those who developed antepartum eclampsia. Since termination of pregnancy is the definitive management of eclampsia, postpartum disease is less likely to proceed because the cause already terminated.
In general overall average time of recovery from eclampsia after admission to the health institutions in East Gojjam zone was short. This is affected by recored time since we cannot get the actual start time of the convulsion. Age dependant management, Prevent recurrent convulsion and special attention for antepartum convulsion are recommended. Prospective forllowup could strentgthen the output.

\section{Limitation of the study}

Since the study was a retrospective follow-up in nature, missing variables were there and many variables are out of analysis because of incompleteness. The start time of

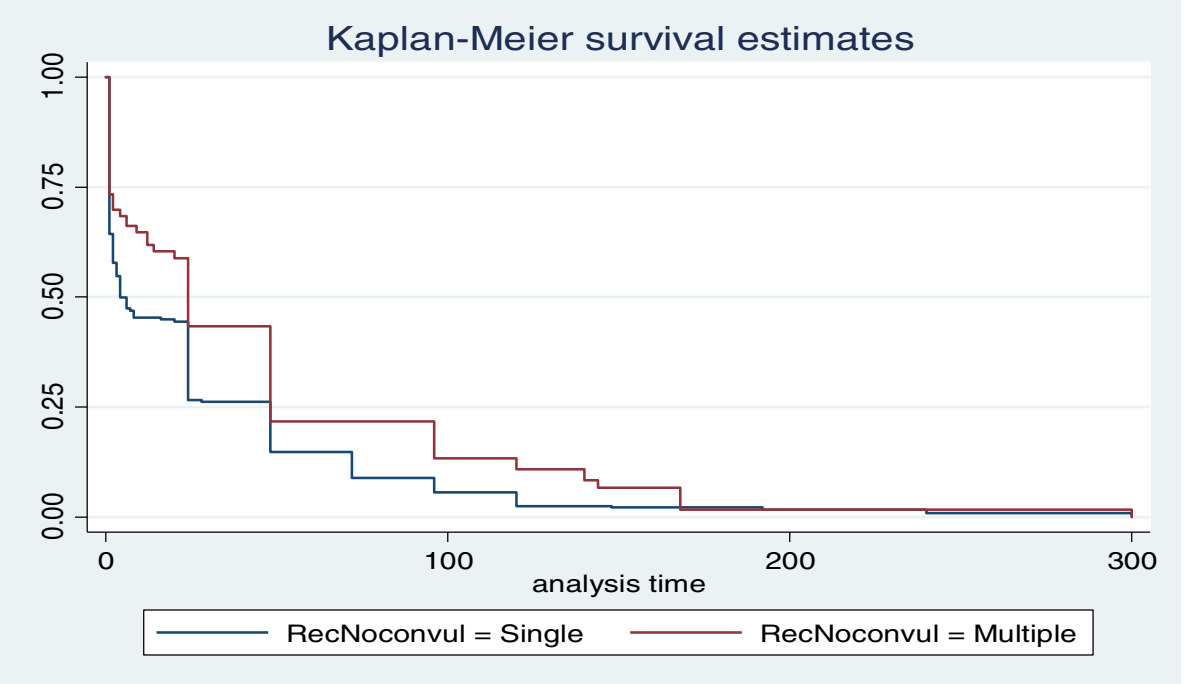

Fig. 2 Kaplan-Meier Survival estimate of time to recovery among single and multiple convulsion groups 2018 
Table 3 Predictors of time to recovery from eclampsia in East Gojjam zone hospitals, 2018: a cox regression report

\begin{tabular}{|c|c|c|c|c|}
\hline Variable & Category & CHR $(95 \% \mathrm{Cl})$ & $\operatorname{AHR}(95 \% \mathrm{Cl})$ & $P$-value \\
\hline \multirow[t]{6}{*}{ Age in years } & $16-19$ & 1 & 1 & \\
\hline & $20-24$ & $0.55(0.35,0.88)$ & $0.50(0.28,0.89)$ & 0.021 \\
\hline & $25-29$ & $0.62(0.39,0.97)$ & $0.48(0.26,0.87)$ & 0.016 \\
\hline & $30-34$ & $0.65(0.41,1.03)$ & $0.53(0.28,1.01)$ & 0.053 \\
\hline & $35-39$ & $0.55(0.34,0.88)$ & $0.40(0.21,0.77)$ & 0.006 \\
\hline & $>=40$ & $0.68(0.38,1.21)$ & $0.45(0.20,0.99)$ & 0.049 \\
\hline \multirow[t]{2}{*}{ Residence } & Urban & 1 & 1 & \\
\hline & Rural & $0.94(0.79,1.11)$ & $0.96(0.77,1.19)$ & 0.722 \\
\hline \multirow[t]{4}{*}{ Parity } & Nulliparous & 1 & & \\
\hline & Primiparous & $1.16(0.65,2.07)$ & & \\
\hline & Multiparous & $1.21(0.68,2.18$ & & \\
\hline & Grand multiparous & $1.12(0.61,2.07)$ & & \\
\hline \multirow[t]{3}{*}{ Gestational age } & $<=33$ weeks & 1 & 1 & \\
\hline & 34-36 weeks & $1.08(0.87,1.30$ & & \\
\hline & $>=37$ weeks & $1.24(1.02,1.50)$ & & \\
\hline \multirow[t]{2}{*}{ Type of pregnancy } & Singleton & 1 & & \\
\hline & Twin & $1.09(0.78,1.52)$ & & \\
\hline \multirow[t]{2}{*}{ ANC follow-up } & Yes & 1 & & \\
\hline & No & $0.91(0.69,1.19)$ & & \\
\hline \multirow[t]{3}{*}{ Mode of delivery } & SVD & 1 & & \\
\hline & $\mathrm{C} / \mathrm{S}$ & $1.06(0.88,1.29)$ & & \\
\hline & Assisted delivery & $096(0.72,1.27)$ & & \\
\hline \multirow[t]{2}{*}{ Place of delivery } & Home & 1 & & \\
\hline & Institution & $1.01(0.69,1.48)$ & & \\
\hline \multirow[t]{2}{*}{ Duration of labor (464) } & $<=12 \mathrm{~h}$ & 1 & 1 & \\
\hline & $>12 \mathrm{~h}$ & $1.25(1.02,1.52)$ & $1.26(1.01,1.57)$ & 0.036 \\
\hline \multirow[t]{2}{*}{ Initiation of labor } & Induced & 1 & & \\
\hline & Spontaneous & $1.09(0.92,1.29)$ & & \\
\hline \multirow[t]{2}{*}{ Number of convulsions from } & Single & 1 & & \\
\hline & Multiple & $0.73(0.60,0.89)$ & $0.68(0.52,0.87)$ & 0.003 \\
\hline \multirow[t]{2}{*}{ Convulsion to administration of anticonvulsant } & Less than an hour & 1 & & \\
\hline & More than an hour & $0.85(0.71,1.03)$ & & \\
\hline \multirow[t]{3}{*}{ Time of occurrence of convulsion } & Antepartum & 1 & 1 & \\
\hline & Intrapartum & $1.54(1.18,2.01)$ & $1.35(0.97,1.88)$ & 0.076 \\
\hline & Postpartum & $1.22(0.911 .63)$ & $1.81(1.17,2.81)$ & 0.008 \\
\hline
\end{tabular}

the follow-up was time of diagnosis of the patient as eclampsia and documented and therefore, this may reduce the duration because of either late diagnosis or late documentation.

Since authors cannot get similar study findings, discussion in comparison with other studies not yet done.

\section{Abbreviations}

AHR: Adjusted hazard ratio; HDP: Hypertensive disorders of pregnancy
Acknowledgements

We would like to give our heartfelt thanks to Debre Markos university and study participants.

Authors' contributions

BK: conceived the concept of the study and design of the study, reviewed studies, performed the analysis and wrote the manuscript. YB, LY, YS, MD and MA, Participated in the design of the study, reviewed studies and wrote the manuscript. All authors revised the article critically for important intellectual content and approved the final manuscript.

\section{Funding}

This study is fully funded by Debre Markos University. 


\section{Availability of data and materials}

The datasets used and/or analyzed during the current study are available from the corresponding author on reasonable request.

\section{Declarations}

\section{Ethics approval and consent to participate}

All methods were carried out in accordance with relevant guidelines and regulations from study design to the analysis. Ethical clearance was obtained from Debre Markos university college of Health science Ethical Review committee, and permission was obtained from the administration and medical director of the selected Hospitals. Since we used retrospective data, the research ethics review committee of Health sciences college, Debre Markos University, waived the need for informed consent. To keep the confidentiality of maternal information data were collected based on their registration number and codes used instead of names.

\section{Consent for publication}

Not applicable.

\section{Competing interests}

The authors declare that they have no competing interests.

\section{Author details}

'Department of Midwifery, College of Health Sciences, Debre Markos University, Debre Markos, Ethiopia. ${ }^{2}$ Department of Public Health, College of Health Sciences, Debre Markos University, Debre Markos, Ethiopia.

\section{Received: 11 November 2020 Accepted: 26 March 2021}

Published online: 14 April 2021

\section{References}

1. World Health Organization: Priority medicines for mothers and children 2011.

2. Sen G, Govender V, Cottingham J. Maternal and neonatal health: surviving the roller-coaster of international policy. Bangalore: Centre for Public Policy, Indian Institute of Management Bangalore; 2007.

3. Zureick-Brown SNH, Chou D, Mizoguchi N, Say L, Suzuki E, Wilmoth J. Understanding global trends in maternal mortality. In: International perspectives on sexual and reproductive health; 2013.

4. World Health Organization U: Trends in maternal mortality: 1990-2015: estimates from WHO, UNICEF, UNFPA, World Bank Group and the U N Population Division. 2015.

5. Alkema LCD, Hogan D, Zhang S, Moller AB, Gemmill A, Fat DM, et al. Global, regional, and national levels and trends in maternal mortality between 1990 and 2015, with scenario-based projections to 2030: a systematic analysis by the UN maternal mortality estimation inter-agency group. Lancet. 2016; 387(10017):462-74. https://doi.org/10.1016/S0140-6736(15)00838-7.

6. Kassebaum NJB-VA, Coggeshall MS, Shackelford KA, Steiner C, Heuton KR, Gonzalez-Medina D, et al. Global, regional, and national levels and causes of maternal mortality during 1990-2013: a systematic analysis for the global burden of disease study 2013. Lancet. 2014;384(9947):980-1004. https://doi. org/10.1016/S0140-6736(14)60696-6.

7. Bongaarts J, WHO U, UNFPA, World Bank Group, and United Nations Population Division. Trends in maternal mortality: 1990 to 2015 Geneva: World Health Organization, 2015. Popul Dev Rev. 2016;42(4):726. https://doi. org/10.1111/padr.12033.

8. WHO U. UNFPA, The World Bank and the United Nations Population Division. Trends in maternal mortality. 1990;2013:1-68.

9. Thomas TNGJ, Lattof SR, Wegner MN, Kearns AD, Langer A. Improved maternal health since the ICPD: 20 years of progress. Contraception. 2014; 90(6):32-8.

10. (WHO). WHO. WHO recommendations for prevention and treatment of preeclampsia and eclampsia. Geneva: WHO; 2011.

11. Johnson AC: Mechanisms of seizure during pregnancy and preeclampsia. University of Vermont ScholarWorks @ UVM 2015, 336.

12. Hill SYA, Bero L. Priority medicines for maternal and child health: a global survey of national essential medicines lists. Plos One. 2012;7(5):e38055. https://doi.org/10.1371/journal.pone.0038055.
13. Demographic IE. Health survey 2016: key indicators report. Addis Ababa, Ethiopia, and Rockville, Maryland, USA. Ethiopia: Ethiopia Demographic and Health Survey. 2016.

14. Tessema GALC, Melaku YA, Misganaw A, Woldie SA, Hiruye A, Amare AT, et al. Trends and causes of maternal mortality in Ethiopia during 1990-2013: findings from the global burden of diseases study 2013. BMC Public Health. 2017;17(1):160. https://doi.org/10.1186/s12889-017-4071-8.

15. Abdella A: Maternal mortality trend in Ethiopia. Ethiop J Health Dev 2010, 24(1).

16. Admasu KHMA, Bailey P. Indicators for availability, utilization, and quality of emergency obstetric care in Ethiopia, 2008. Int J Gynecol Obstet. 2011; 115(1):101-5. https://doi.org/10.1016/j.ijgo.2011.07.010.

17. Godefay H BP, Kinsman J, Mulugeta $A_{i}$ : Understanding maternal mortality from top-down and bottom-up perspectives: Case of Tigray Region, Ethiopia. J Glob Health 2015 5(1)

18. Berhan YEG. Maternal mortality predictors in women with hypertensive disorders of pregnancy: a retrospective cohort study. Ethiop J Health Sci. 2015;25(1):89-98. https://doi.org/10.4314/ejhs.v25i1.12.

19. Le Blanc D. Towards integration at last? The sustainable development goals as a network of targets. Wiley Online Library. 2015;23(3):176-87.

20. Makkonen NHM, Kirkinen P. Postpartum recovery after severe pre-eclampsia and HELLP-syndrome. J Perinat Med. 1996;24(6):641-9.

\section{Publisher's Note}

Springer Nature remains neutral with regard to jurisdictional claims in published maps and institutional affiliations.
Ready to submit your research? Choose BMC and benefit from:

- fast, convenient online submission

- thorough peer review by experienced researchers in your field

- rapid publication on acceptance

- support for research data, including large and complex data types

- gold Open Access which fosters wider collaboration and increased citations

- maximum visibility for your research: over $100 \mathrm{M}$ website views per year

At $\mathrm{BMC}$, research is always in progress.

Learn more biomedcentral.com/submission 